\title{
Investigation of optimum gating system design of fused deposition modelling pattern for sand casting
}

\author{
S. Maidin*, T. M. YI, A. Hambali, S. Akmal, R. H. Hambali and Z. Abdullah \\ Advanced Manufacturing Centre, Universiti Teknikal Malaysia Melaka, \\ Hang Tuah Jaya, 76100 Durian Tunggal, Melaka, Malaysia \\ Email: shajahan@utem.edu.my \\ Phone: +6063316897; Fax: +6063316411
}

\begin{abstract}
Sand casting is a process of pouring molten metal into a mould. The quality of the casting highly depends on the pattern and mould involving the gating system design. Inappropriate gating system design leads to casting defects. Moreover, conventional sand casting pattern production is time consuming, expensive and unable to produce complex patterns. This research therefore studies the feasibility of using the Fused Deposition Modelling system as a rapid tooling process to produce a sand casting pattern. To do this, three concepts of the gating system designated by the location and size of sprue and riser were generated using the CAD software. In order to select the optimum gating system design, ANSYS software was employed to analyse the filling process based on eight ranking criteria which included static pressure, density all, velocity magnitude, total temperature, internal energy, turbulent viscosity, wall shear stress and velocity streamline. Based on the simulation results, the concept that comprised of the sprue and riser measured $20 \mathrm{~mm}$ diameter and designed on both sides of the hand wheel was selected as the optimum design of the gating system since it scored the highest mark in the eight ranking criteria. Then, the actual casting of the hand wheel was produced. In order to validate the results of the simulation, surface roughness and dimension accuracy were done. The sprue and riser that measured $20 \mathrm{~mm}$ in diameter showed smoother texture and this dimension was the closest to the ideal dimension. The results also showed that the sprue and riser located on the top of the connector of the hand wheel demonstrated the worst surface finish and dimensional accuracy due to imbalance between molten metal flow through the sprue and riser.
\end{abstract}

Keywords: Fused Deposition Modelling; sand casting; hand wheel; gating system design.

\section{INTRODUCTION}

Sand casting is an important manufacturing process in industries today. It is an economic method for mass production of complex metal products. However, conventional method of manufacturing sand casting pattern has not been able to meet customer satisfaction due to its difficulty of producing complex and intricate parts, either in wood or metal patterns. The wood pattern fails to produce thin parts while the metal pattern fails to produce complex shapes and contour parts [1]. Moreover, the conventional manufacturing cycle time of sand casting pattern is long due to involvement of manual manufacturing method and manpower. In today's market of intense competition, longer lead time may cause a customer to lose faith from the economic viewpoint. In addition, the tooling cost of the 
conventional manufacturing method of sand casting is high. It is not suitable for manufacturing in small quantity [2]. Hence, this research studies the feasibility of using pattern produced via an FDM system as a rapid tooling process to produce a sand casting pattern. It is believed that the application of rapid tooling is able to minimise the lead time and cost to manufacture sand casting pattern [2]. Next, casting quality has become an important issue in manufacturing industries. This is because the casting quality is one of the main factors that affects production cost. Design plays an important role to produce a good quality casting product [3]. A few researches have reported that mainly $90 \%$ of the casting defects came from an inappropriate design of the gating system [4]. The wrong gating system design will cause surface roughness and shrinkage cavity to happen in the sand casting. Meanwhile, current practices on designing and casting mould are based on trial and error which solely depend on the engineer's experience and knowledge. Undoubtedly, this method consumes manufacturing time and cost. Hence, CAD design and simulation software were utilised to optimise the gating system design in this study as it will ensure a smooth flow of molten metal along the pattern during the sand casting process and have better surface finish of the final casting product.

\section{Sand Casting}

Casting is a process of producing the desired parts by pouring metal or alloy which is in liquid form into a prepared mould. Then, the liquid in the mould is allowed to cool and solidify to form pieces of metal or alloy. This process is called sand casting. The modern casting industries demand less defects in the dimensional accuracy of products. Therefore, it is important for them to produce components with good properties and accuracy [5].

\section{Casting Defects}

The quality of casting is always the main issue in manufacturing industries as it affects the manufacturing cost of product [4]. There are various casting defects that happen in the casting process. Casting defects refer to any irregularity in the moulding process causing defects in casting. These casting defects can be improved by practicing proper moulding methods such as welding and metallisation. There are five common casting defects that happened in the casting process, such as gas defect, shrinkage cavities, moulding material defects, pouring metal defect and metallurgical defect [6]. Free from casting defect is always a primary goal to be achieved in the present casting arena. This is because reduced casting defects can save energy and cost.

\section{Gating System}

Gating system is one of the most important criteria for designing sand casting mould. It is usually comprised of a pouring cup, sprue, runner and riser. At first, the liquid metal is poured into the pouring cup. The metal then flows from the pouring cup to the sprue. Runner is a channel to allow the molten metal to pass through the gate and enter into the mould cavity. Meanwhile, riser is connected to the gating system. The riser is used to fill the mould cavity during the solidification process. Hence, the gating system plays an important role in sand casting. Inappropriate design of gating system will cause filling related defects such as shrinkage cavity and surface roughness. There are seven basic rules for a gating system.

i) Gating system should be designed for rapid mould filling. This is because heat loss during the molten metal filling process can cause premature freezing of mould. 
ii) Gating system should be designed for minimising turbulence. This is because turbulent flow between gating system and mould cavity increases the mechanical and thermal attacks within the mould. Hence, bubbles will be formed on the surface of the product.

iii) Gating system should be designed to prevent mould and core erosion. This is because high flow velocity or inappropriate flow direction will erode the mould surface and form casting defects.

iv) Gating system should be designed in a desirable thermal gradient to avoid the formation of hot spot.

v) Gating system should be designed for maximising yield. The quantity of metal contained in the gating system should be minimised in order to reduce production cost

vi) Gating system should be designed for easy to remove. The quantity and size of ingate connection should be minimised to reduce the finishing operation cost. vii) Gating system should be designed to prevent distortion. This is due to uneven heat distribution which can result in an undesirable solidification condition and cause distortion.

\section{Design Rules of Riser}

Riser acts as reservoirs to feed molten metal to the mould cavity to avoid solidification shrinkage. Hence, the riser is designed to solidify after the feeding process. This is because riser can continuously feed the molten metal into the entire mould cavity and thus prevent casting shrinkage. However, riser decreases metal usage rate while increases the casting cooling time. Hence, the proper riser size should be designed to satisfy feeding with the smallest volumE. there are four basic design rules for a riser.

i) Riser should be developed in an optimised design so that it can feed the molten metal with the right amount, right place and right time.

ii) Riser should be designed for easy removal in order to reduce production cost.

iii) Riser size and quantity should be minimised to enhance mould yield and to reduce production costs.

iv) Riser should be designed in the right location in order to reduce casting defects such as shrinkage and distortion.

\section{Additive Manufacturing}

The word additive manufacturing (AM) is derived from rapid prototyping (RP). AM has been studied for more than 30 years and has vast applications such as developing prototypes for product development process, manufacturing functional and end-use parts for other applications [7]. According to [8], AM is the use of additive fabrication technology to produce useable products or parts. Meanwhile, [9] defined that AM is an advanced technology where products are designed by computer-aided design (CAD) software and then developed by thin layers of materials. Hence, AM has no boundaries on design and its manufacturability. Some examples of AM processes include stereolithography, selective laser sintering, fused deposition modelling, and 3D printing, which shares a generic process but parts are produced via different methods and materials.

\section{Rapid Tooling}

In sand casting, additive manufacturing is a preferable method to produce intricate parts that are difficult to be achieved by the conventional manufacturing processes. The advantage of additive manufacturing is the capability to produce complex, small and 
delicate parts within a short time, where the use of wooden based pattern would be difficult [1]. The process is versatile and uses less tooling as compared to the traditional method, which in the end can reduce the cost of production. In addition, RP technology enables design engineers to detect economic visibility and sand cast defect in the first attempt. In recent developments, the use of internet technologies would facilitate better communication to assist the design process in additive manufacturing [2]. Therefore, tooling costs and product development times can be decreased by more than 75 percent with the aid of rapid tooling and related technologies [10].

\section{METHODS AND MATERIALS}

This research started off by designing three conceptual designs of the gating system for a hand wheel. The reason for having only three conceptual designs of the gating system is because it is appropriate for the location of the sprue and riser on the hand wheel and it is sufficient for the optimisation study. The hand wheel was chosen for this study because it is relatively easy to design and to analyse the results of the casting later. The concept designs of the gating system for the hand wheel were generated by varying the locations of sprue and riser on the hand wheel and its dimensions. CAD software was used to produce these concept designs. Then, ANSYS fluent simulation software was used to simulate the filling process for these three mould design concepts. In order to compare the concept designs, eight ranking criteria including static pressure, density all, velocity magnitude, total temperature, internal energy, turbulent viscosity, wall shear stress and velocity streamline were analysed. Based on the simulation results, optimum runner and gating system design were selected as the final concept design. In order to start the simulation process, the option of Fluid Flow (Fluent) in the ANSYS 16.0 software was chosen. The geometry was imported by browsing the desired CAD file. The material of the model was set as tin, and the density was $5770 \mathrm{~kg} / \mathrm{m}^{3}$, specific heat was $213 \mathrm{j} / \mathrm{kg}-\mathrm{k}$, thermal conductivity was $63.2 \mathrm{w} / \mathrm{m}-\mathrm{k}$ and viscosity was $0.00145 \mathrm{~kg} / \mathrm{m}-\mathrm{s}$. A desktop FDM machine was used to manufacture the hand wheel pattern and the gating system design that was selected. In order to validate the simulation results, sand casting process was carried out based on the best and worst design concepts. There were two parameters used to conduct the comparison between these two hand wheel products: surface roughness and dimension. Surface roughness tester was used to measure the surface roughness of the hand wheel product. Meanwhile, venire calliper was used to measure the dimension of the hand wheel product. These two parameters were important to prove how close the value of the hand wheel product was compared to the ideal dimension.

\section{Conceptual Design for the Gating System}

Table 1 shows three conceptual designs of the gating system for a hand wheel. For Concept 1, the sprue and the riser were designed on both sides of the hand wheel. For Concept 2, the sprue was designed at the side of the hand wheel while sprue was designed on top of the connector. Lastly, for Concept 3, the sprue and riser were designed on top of the connector. There were three different diameters of sprue and riser for the simulation process in order to obtain the optimum hand wheel casting mould design. 
Table 1. Three conceptual designs of a hand wheel gating system.

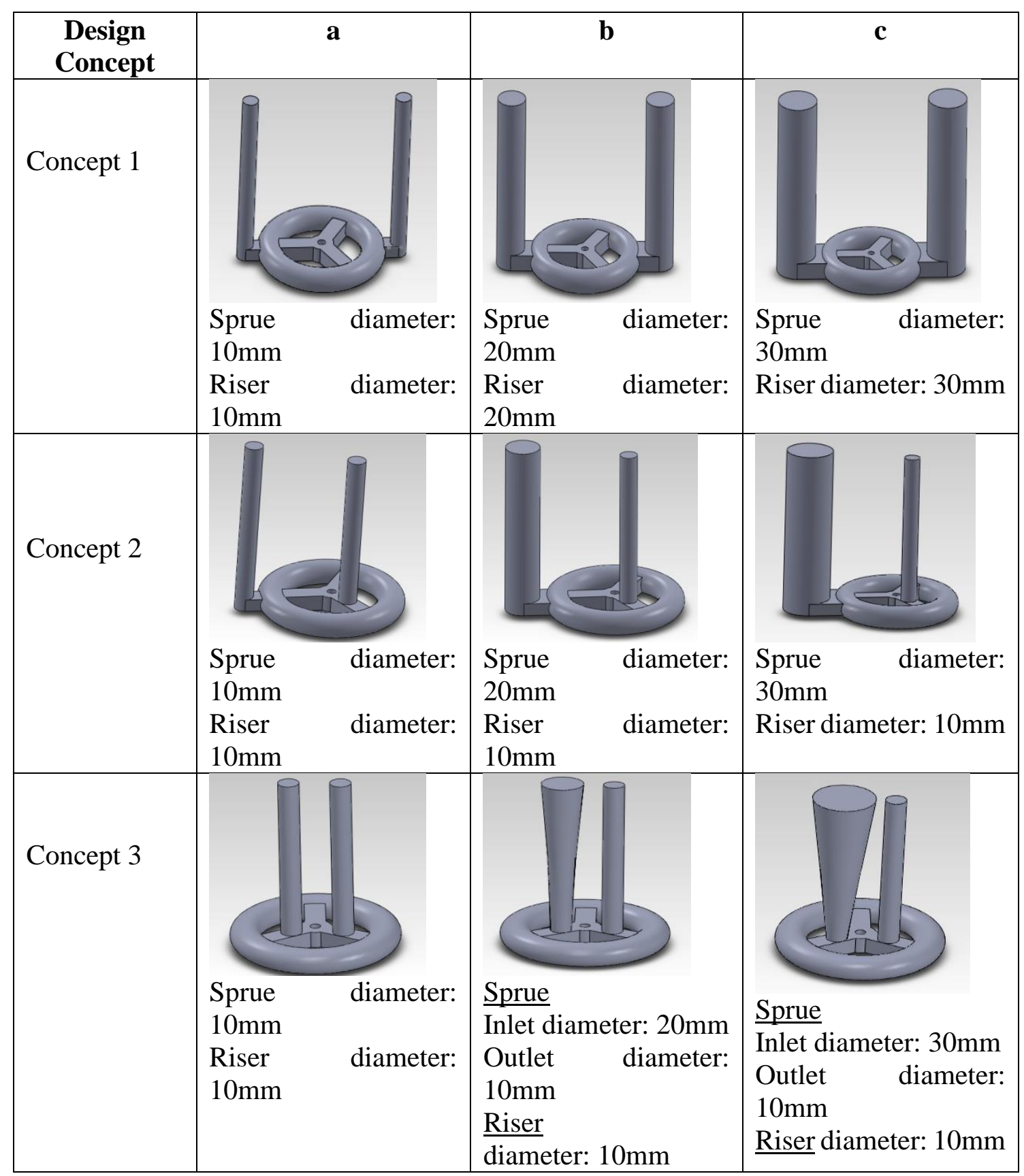

\section{RESULTS AND DISCUSSION}

\section{Simulation Results}

There were eight parameters analysed in order to select the best design concept. These parameters are static pressure, density, velocity magnitude, total temperature, internal energy, turbulent viscosity, wall shear stress and velocity streamline. Figure 1 shows examples of the results for Concept 1(a). 


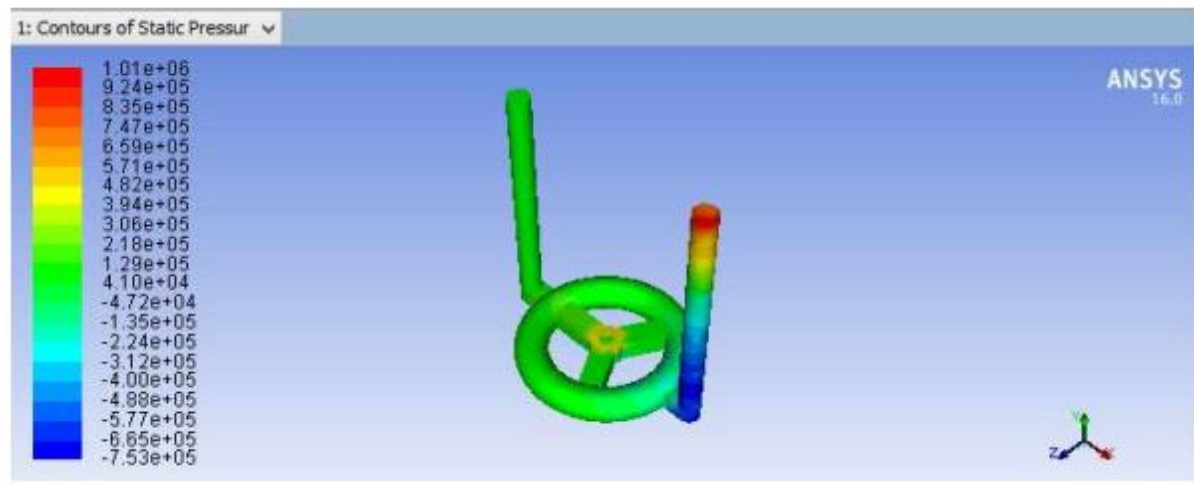

(a) Static Pressure

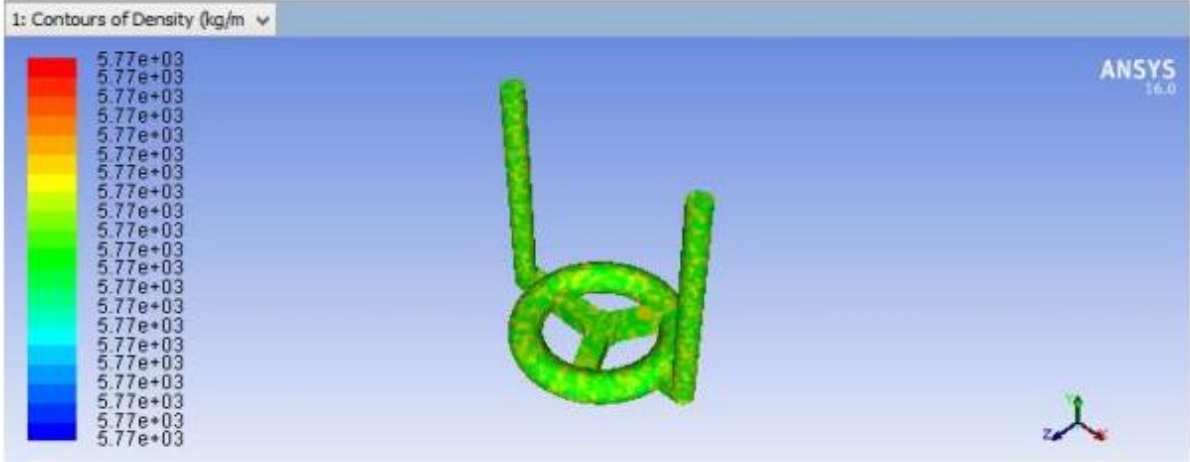

(b) Density

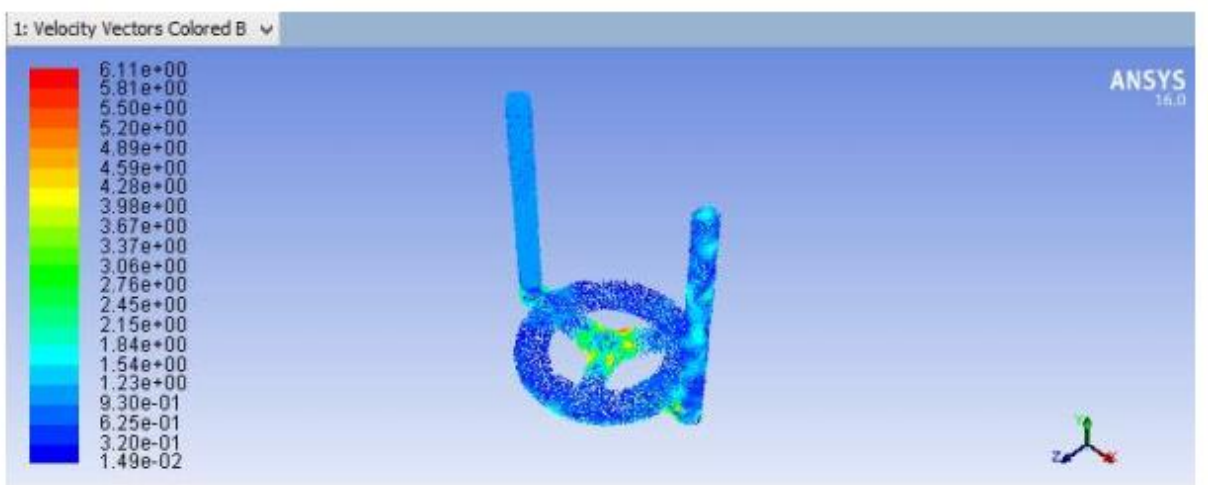

(c) Velocity magnitude

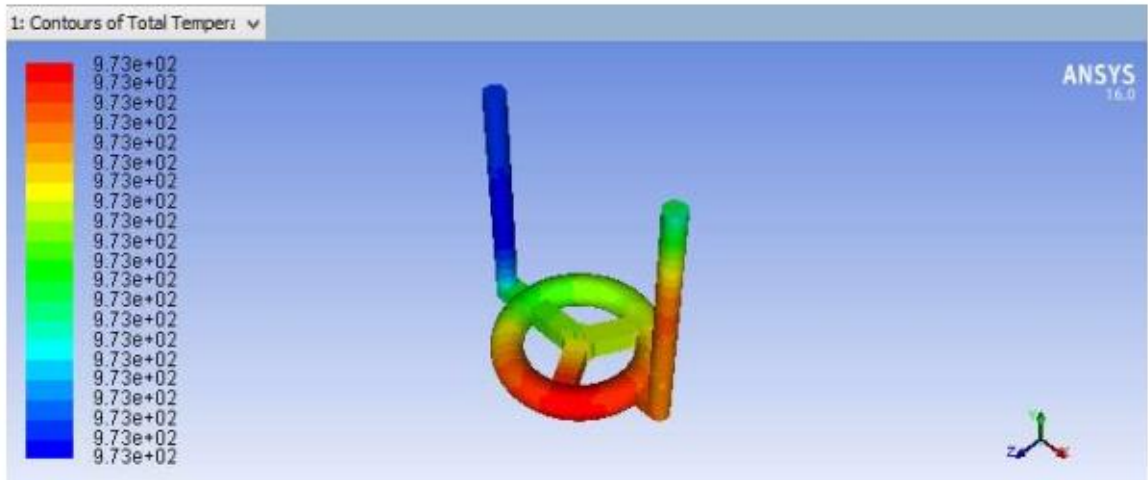

(d) Total temperature

Figure 1. Contour of static pressure, density, velocity magnitude, total temperature, internal energy, turbulent viscosity, wall shear stress and velocity streamline. 


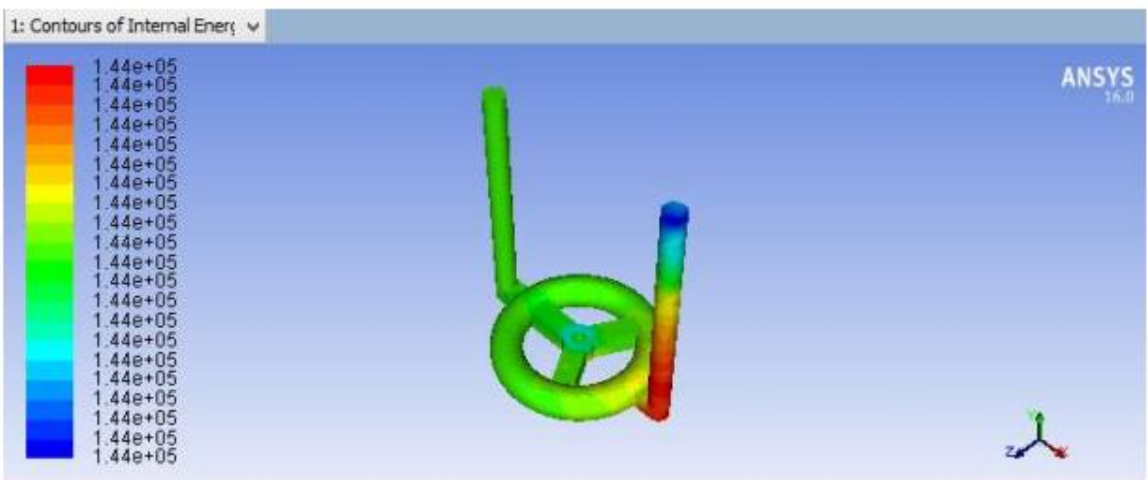

(e) Internal energy

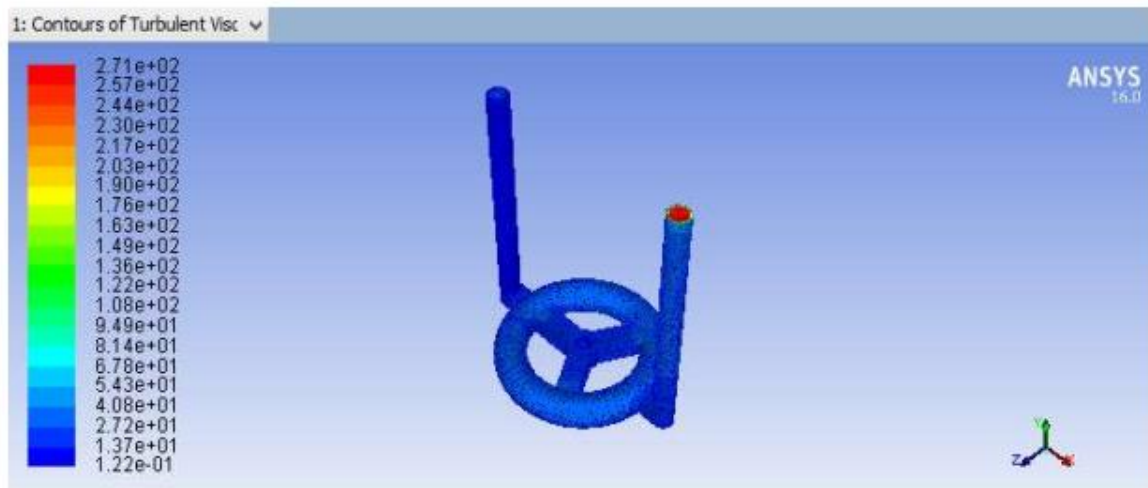

(f) Turbulent viscosity

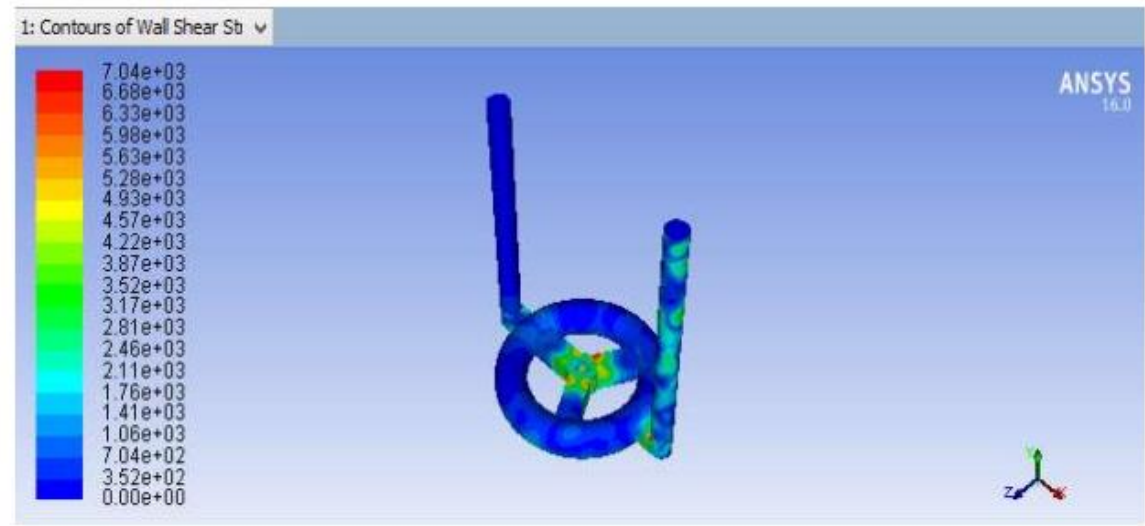

(g) Wall Shear Stress

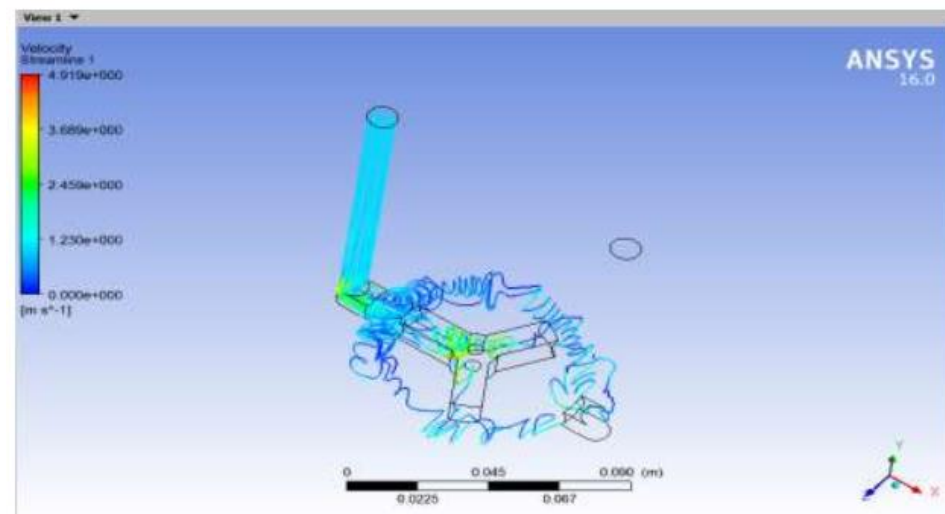

(h) Velocity Streamline

Figure 1. Continued. 
For Concept 1(a), the minimum static pressure was $-753162.9 \mathrm{~Pa}$ and maximum static pressure was $1011747 \mathrm{~Pa}$. The minimum density value was $5769.997 \mathrm{~kg} / \mathrm{m}^{3}$ and maximum density value was $5770.002 \mathrm{~kg} / \mathrm{m}^{3}$. The minimum velocity magnitude was $0.01489078 \mathrm{~m} / \mathrm{s}$ and maximum velocity magnitude was $6.114361 \mathrm{~m} / \mathrm{s}$. The minimum total temperature was $972.998 \mathrm{k}$ and maximum total temperature was $973.0322 \mathrm{k}$. The minimum internal energy was $143552.2 \mathrm{j} / \mathrm{kg}$ and maximum internal energy was 143862.4 $\mathrm{j} / \mathrm{kg}$. The minimum turbulent viscosity was $0.1223691 \mathrm{~kg} / \mathrm{m}-\mathrm{s}$ and maximum turbulent viscosity was $271.0001 \mathrm{~kg} / \mathrm{m}$-s. The maximum wall shear stress was $7035.975 \mathrm{~Pa}$. The velocity streamline was not smooth and fluid flow did not reach the outlet. From the simulation results for all the concepts, data were then analysed so as to select the optimum design concept. In order to select the optimum design concept in terms of static pressure, velocity magnitude and total temperature, the value of the concept should be nearest to the average value of parameters. The reason for this was because the average static pressure will ensure a smooth flow of molten metal along the pattern during the sand casting process [6]. Meanwhile, when the value of velocity magnitude was either too high or too low, it will affect the sand casting process and cause casting defects such as misrun and blow holes (Chaudhari \& Thakkar, 2014). In addition to that, optimum temperature can avoid the formation of casting defects to the product. On the other hand, in order to select the optimum design concept in terms of internal energy and wall shear stress, the lowest value will be selected first [6]. In order to avoid casting defects, it is preferred to form internal energy of solid particles lower than the surrounded liquid during the nucleation stage. Meanwhile, low wall shear stress can ensure smooth flow of molten metal along the mould cavity and prevent casting defect. Hence, for static pressure and velocity magnitude parameters, Concept 1(b) was selected as the optimum design concept because the value of Concept 1(b) was nearest to the average value. However, Concept 1(c) was selected in terms of total temperature because the value of Concept 1(c) was nearest to the average value. Meanwhile, Concept 3(a) was chosen for the parameter of internal energy because it scored the lowest value of internal energy. In terms of wall shear stress, Concept 1(a) was selected as it scored the lowest value which ensured the smooth flow of molten metal along the mould cavity. For the criteria of density all and turbulent viscosity, all design concepts were accepted since there was no significant difference between these three concepts.

Based on the simulation results obtained from each concept design, it was shown that Concept 1(b) scored the best velocity streamline as molten fluid flowed smoothly throughout the mould. Meanwhile, Concept 1(c) scored number two in terms of velocity streamline. Even though the velocity streamline of Concept 1(c) was as smooth as Concept 1(b), there was a pre-solidification spot that occurred on the bottom side of the mould. Next, Concepts 2(b) and 3(c) scored number three among the design concepts as molten fluid roughly flowed through the mould. Then, Concept 1(a) scored number four among the design concepts as molten fluid cannot flow through the riser. Next, Concepts 2(a), 2(c) and 3(b) scored the second lowest among the design concepts in terms of velocity streamline. This was due to the molten fluid that only flowed through the third quarter of the mould. Last but not least, Concept 3(b) was the worst design as the molten fluid only flowed through one fifth of the mould.

\section{Concept Ranking}

Table 2 shows the concept ranking for the three design concepts. The ranking number for each parameter was determined by the simulation results. It showed that Concept 1(b) scored the highest ranking number at 68. The reason was because Concept 1(b) had an 
excellent performance in terms of static pressure, velocity magnitude and velocity streamline. Hence, the ranking number for these three parameters was 10 . Since the values of density all and turbulent viscosity had no significant difference among these three concepts, the ranking number was set as nine excluding Concept 3(b). The reason was because Concept 3(b) scored 38 with the ranking number of eight for the parameter of density all. Moreover, Concept 1(b) scored the ranking number of five, eight and seven for parameters of total temperature, internal energy and wall shear stress.

Table 2. Concept ranking.

\begin{tabular}{lccccccccc}
\hline $\begin{array}{l}\text { Concept } \\
\text { /Criteria }\end{array}$ & $1(\mathrm{a})$ & $1(\mathrm{~b})$ & 1 (c) & 2(a) & 2(b) & 2 (c) & $3(\mathrm{a})$ & $3(\mathrm{~b})$ & $3(\mathrm{c})$ \\
\hline $\begin{array}{l}\text { Static } \\
\text { pressure }\end{array}$ & 8 & 10 & 5 & 4 & 7 & 3 & 6 & 9 & 1 \\
$\begin{array}{l}\text { Density all } \\
\text { Velocity }\end{array}$ & 9 & 9 & 9 & 9 & 9 & 9 & 9 & 8 & 9 \\
$\begin{array}{l}\text { magnitude } \\
\text { Total }\end{array}$ & 1 & 5 & 10 & 4 & 6 & 3 & 6 & 8 & 9 \\
$\begin{array}{l}\text { temperature } \\
\text { Internal }\end{array}$ & 5 & 8 & 3 & 7 & 2 & 4 & 9 & 6 & 1 \\
$\begin{array}{l}\text { nergy } \\
\text { Turbulent } \\
\text { viscosity }\end{array}$ & 9 & 9 & 9 & 9 & 9 & 9 & 9 & 9 & 9 \\
$\begin{array}{l}\text { Wall shear } \\
\text { stress }\end{array}$ & 10 & 7 & 4 & 9 & 6 & 2 & 8 & 5 & 1 \\
$\begin{array}{l}\text { Velocity } \\
\text { streamline }\end{array}$ & 5 & 10 & 9 & 4 & 7 & 4 & 2 & 4 & 7 \\
\hline
\end{tabular}

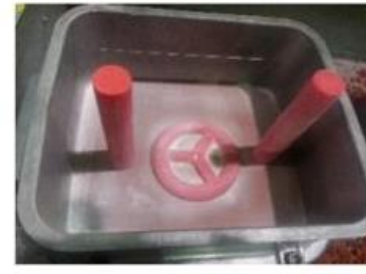

(a)

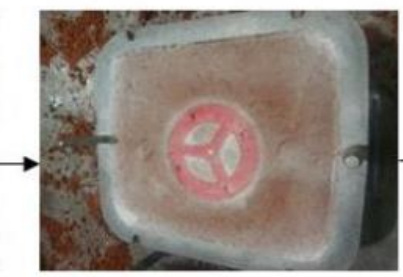

(b)

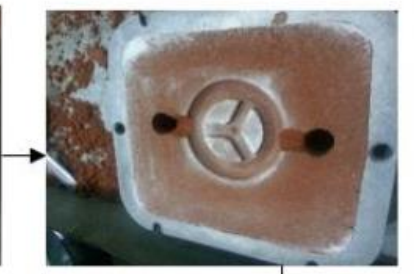

(c)

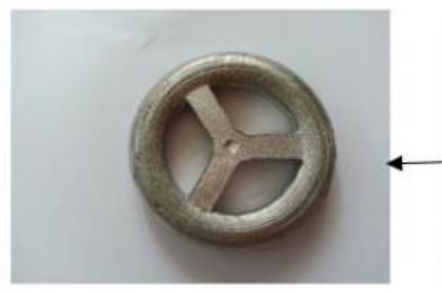

(f)

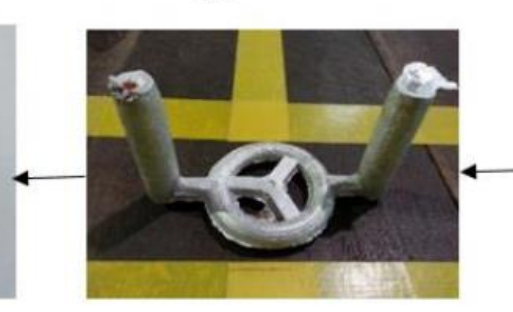

(e)

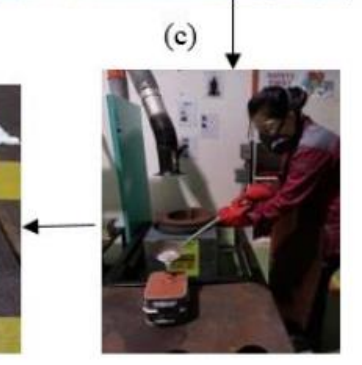

(d)

Figure 2. (a) pour sand into mould, (b) compact the sand, (c) remove pattern, (d) pouring process, (e) sand cast product, (f) final product after finishing process.

\section{Sand Casting Process}

Figure 2 shows the sand casting process. First, the hand wheel pattern was printed with an FDM system. Then, it was used to mould the sand mixture into the shape of casting. Sand was compacted around the pattern. Then, mould cavity was produced by removing the pattern. Sand casting mould was then completed by core making and the gating 
system. Then, tin was melted by furnace and poured into the mould through sprue. The molten tin was cooled and solidified to become a hand wheel. The hand wheel was ready to be removed from the mould. The sprue and riser were then cut off. Lastly, the hand wheel underwent the cleaning and finishing process.

\section{Validation}

Based on the results of ANSYS fluent simulation and the ranking process, Concept 1(b) was the best design concept while Concept 3(c) was the worst design concept. This was because Concept 1(b) scored the highest ranking number, 68 while Concept 3(c) scored the lowest ranking number, 38. In order to validate the results of the simulation findings, sand casting processes were carried out and the pattern produced was compared in terms of surface roughness and dimensional accuracy.

\section{Surface roughness}

Mitutoyo Surface Roughness Tester SJ-301 was used to measure the surface roughness of the hand wheel product for Concepts 1(b) and 3(c). There were a total of seven areas measured in the cast hand wheel as shown in Figure 3. Moreover, measurements were taken 10 times at the surrounding of each area for accuracy. Then, the average value of surface roughness was calculated. The surface roughness result from each cast hand wheel was then compared. Table 3 and Table 4 show surface roughness values taken for Concept 1(b) and Concept 3(c), respectively.

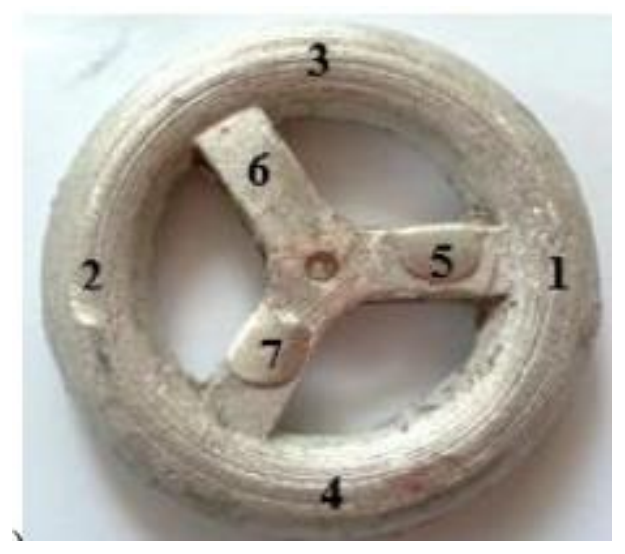

Figure 3. Surface roughness measurement points.

Table 3. Surface roughness value for Concept 1(b).

\begin{tabular}{cccccccccccc}
\hline Area & \multicolumn{10}{c}{ Test $(\mu \mathrm{m})$} \\
\cline { 2 - 13 } & 1 & 2 & 3 & 4 & 5 & 6 & 7 & 8 & 9 & 10 & Ave \\
\hline 1 & 0.94 & 0.93 & 0.98 & 1.11 & 0.80 & 0.70 & 0.57 & 1.00 & 0.86 & 0.53 & 0.84 \\
2 & 0.59 & 0.37 & 0.30 & 0.34 & 0.33 & 1.31 & 0.66 & 0.82 & 0.58 & 1.01 & 0.63 \\
3 & 0.78 & 0.60 & 0.46 & 0.46 & 0.54 & 1.21 & 0.63 & 0.82 & 0.39 & 0.57 & 0.65 \\
4 & 0.24 & 0.38 & 0.83 & 1.34 & 1.17 & 0.32 & 0.49 & 0.45 & 0.44 & 0.75 & 0.64 \\
5 & 0.69 & 0.71 & 0.92 & 0.68 & 1.88 & 1.27 & 0.73 & 1.41 & 1.06 & 1.15 & 1.05 \\
6 & 1.27 & 1.43 & 0.82 & 1.56 & 0.64 & 0.49 & 0.71 & 1.00 & 1.61 & 0.67 & 1.02 \\
7 & 1.21 & 0.77 & 0.83 & 1.15 & 1.80 & 1.14 & 1.00 & 1.03 & 1.42 & 0.91 & 1.13 \\
\hline \multicolumn{1}{l}{} & & & & & & & & & Total average & 0.60 \\
\hline
\end{tabular}


In terms of surface roughness, the smaller the value, the smoother the surface. There were a total of seven areas to be measured in terms of surface roughness. A portable surface roughness tester was used to measure the surface roughness for Concept 1(b) and 3(c). From the values obtained, the range of surface roughness for Concept 1(b) was between $0.63 \mu \mathrm{m}$ to $1.13 \mu \mathrm{m}$. Meanwhile, the range of surface roughness for Concept 3(c) was between 0.72 to $1.71 \mu \mathrm{m}$. It was shown that Concept 3(c) had a larger range of surface roughness than Concept 1(b). In addition, the average surface roughness value of Concept 1(b) was $0.60 \mu \mathrm{m}$. Compared to Concept 1(b), the average surface roughness value of Concept 3(c) was $0.89 \mu \mathrm{m}$. Hence, it was shown that Concept 1(b) had a smoother surface texture compared to Concept 3(c).

Table 4. Surface roughness value for Concept 3(c).

\begin{tabular}{cccccccccccc}
\hline Area & \multicolumn{10}{c}{ Test $(\mu \mathrm{m})$} \\
\cline { 2 - 12 } & 1 & 2 & 3 & 4 & 5 & 6 & 7 & 8 & 9 & 10 & Ave \\
\hline 1 & 1.00 & 0.85 & 1.04 & 0.66 & 1.22 & 0.93 & 0.53 & 1.08 & 1.34 & 1.56 & 1.02 \\
2 & 1.85 & 0.81 & 0.97 & 1.49 & 1.76 & 0.90 & 2.74 & 0.96 & 0.73 & 1.05 & 1.33 \\
3 & 0.83 & 2.28 & 0.91 & 0.82 & 0.93 & 0.61 & 0.85 & 0.95 & 1.25 & 1.27 & 1.07 \\
4 & 0.79 & 0.61 & 0.71 & 0.50 & 0.78 & 0.54 & 0.58 & 1.28 & 0.76 & 0.64 & 0.72 \\
5 & 1.96 & 2.24 & 1.18 & 1.45 & 1.68 & 1.22 & 0.91 & 0.96 & 2.00 & 1.74 & 1.53 \\
6 & 1.76 & 1.54 & 1.76 & 1.83 & 1.73 & 1.88 & 1.16 & 2.85 & 1.05 & 1.57 & 1.71 \\
7 & 1.46 & 1.41 & 1.17 & 1.45 & 2.62 & 1.52 & 0.64 & 1.78 & 1.11 & 1.52 & 1.47 \\
\hline \multicolumn{1}{l}{} & & & & & & & & & Total average & 0.89 \\
\hline
\end{tabular}

\section{Dimensional Accuracy}

Vernier caliper was used to measure the dimension of hand wheel casting for Concepts 1(b) and 3(c). There were five areas measured as shown in Figure 4. Area A represented the total length of hand wheel; area $\mathrm{B}$ represented the diameter of wheel; areas C, D and E represented the length of connector. Meanwhile, Table 5 shows the ideal dimension of a hand wheel pattern. In order to obtain the accuracy of the hand wheel dimension, measurements were taken for five times at each point. The average value of dimension for each point was then calculated. The results were compared. Table 6 and Table 7 show the dimension measurement values taken from Concept 1(b) and Concept 3(c), respectively.

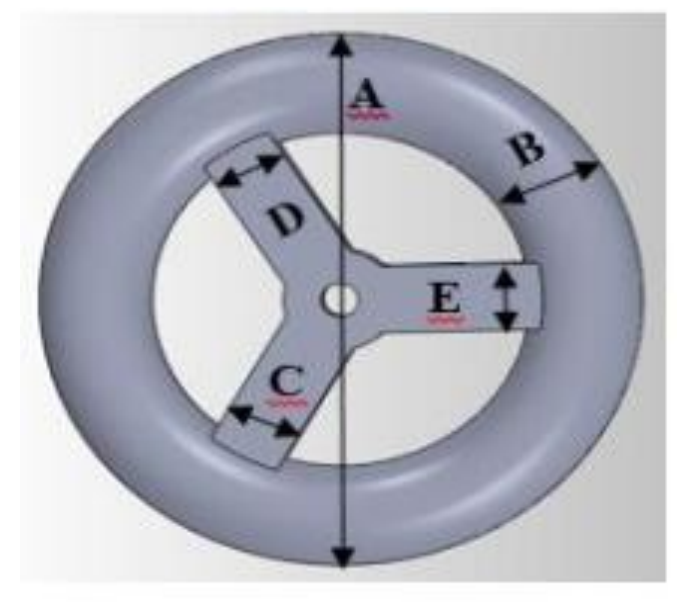

Figure 4. Dimension measurement points. 
Table 5. Ideal dimension of hand wheel pattern.

\begin{tabular}{cc}
\hline Area & Ideal dimension $(\mathrm{mm})$ \\
\hline A & 80 \\
B & 15 \\
C & 10 \\
D & 10 \\
E & 10 \\
\hline
\end{tabular}

Table 6. Dimension measurement values taken from Concept $1 \mathrm{~b}$.

\begin{tabular}{cccccccc}
\hline $\begin{array}{c}\text { Measurement }(\mathrm{mm}) / \\
\text { Area }\end{array}$ & 1 & 2 & 3 & 4 & 5 & Average & Difference \\
\hline A & 79.70 & 80.00 & 79.85 & 79.78 & 79.96 & 79.86 & 0.14 \\
B & 15.00 & 14.98 & 14.95 & 15.05 & 14.90 & 14.98 & 0.02 \\
C & 10.08 & 10.12 & 10.02 & 10.16 & 10.18 & 10.11 & 0.11 \\
D & 10.02 & 10.13 & 10.07 & 10.14 & 10.16 & 10.10 & 0.10 \\
E & 10.00 & 10.12 & 10.08 & 10.17 & 10.20 & 10.11 & 0.11 \\
\hline
\end{tabular}

Table 7. Dimension measurement values taken from Concept 3c.

\begin{tabular}{cccccccc}
\hline $\begin{array}{c}\text { Measurement } \\
(\mathrm{mm}) \text { / Area }\end{array}$ & 1 & 2 & 3 & 4 & 5 & Average & Difference \\
\hline A & 80.00 & 80.40 & 79.90 & 79.62 & 78.30 & 79.64 & 0.36 \\
B & 15.06 & 14.72 & 14.82 & 15.00 & 14.72 & 14.86 & 0.14 \\
C & 10.50 & 10.60 & 10.40 & 10.16 & 9.72 & 10.28 & 0.28 \\
D & 10.00 & 10.20 & 10.10 & 10.16 & 10.30 & 10.15 & 0.15 \\
E & 10.32 & 10.68 & 10.38 & 10.10 & 10.24 & 10.34 & 0.34 \\
\hline
\end{tabular}

In terms of dimension, the closer the value of the cast hand wheel dimension to the ideal dimension, the better the accuracy obtained. The dimensions of Concepts 1(b) and 3(c) were measured. There were a total of five areas to be measured in terms of dimension, which were areas A to E. For area A, Concept 1(b) was deviated $0.14 \mathrm{~mm}$ from the ideal dimension while Concept 3(c) deviated $0.36 \mathrm{~mm}$ from the ideal dimension. Meanwhile, for area B, Concept 1(b) deviated $0.02 \mathrm{~mm}$ from the ideal dimension and Concept 3(c) deviated $0.14 \mathrm{~mm}$ from the ideal dimension. For area C, Concept 1(b) had a deviation value of $0.11 \mathrm{~mm}$ while Concept $3(\mathrm{c})$ had a deviation value of $0.28 \mathrm{~mm}$. Next, Concept 1(b) had a $0.10 \mathrm{~mm}$ deviation value and Concept 3(c) had a $0.15 \mathrm{~mm}$ deviation value in area $\mathrm{D}$. Last but not least, Concept $1 \mathrm{~b}$ obtained $0.11 \mathrm{~mm}$ deviation value for area E, compared to Concept 3(c) which obtained a $0.34 \mathrm{~mm}$ deviation value. From the measurement value, it was proven that the dimension of Concept 1(b) was closer to the ideal dimension compared to Concept 1(c). This was because Concept 1(b) had a smaller deviation value between the real casting product and ideal dimension. By comparing surface roughness and dimension accuracy between these two cast hand wheels, it was proven that Concept 1(b) achieved the better results compared to Concept 3(c). Hence, the simulation results were validated. 


\section{CONCLUSIONS}

The study investigated the optimum design of the gating system for a hand wheel. Three Concept designs of the gating system for a hand wheel were developed and validated based on eight ranking criteria such as static pressure, density, velocity magnitude, total temperature, internal energy, turbulent viscosity, wall shear stress and velocity streamline. As a conclusion, accurate location and adequate diameter of sprue and riser demonstrated excellent performance in terms of static pressure, velocity and streamline total temperature, internal energy and wall shear stress. Such criteria resulted in fine surface finish and dimension accuracy of the end product. In this study, Concept $1 \mathrm{~b}$ which was designed with the sprue and riser measured at $20 \mathrm{~mm}$ in diameter was selected as it scored the highest mark of 68 due to its excellent performance as compared to the other concepts. Besides, the dimension of Concept $1 \mathrm{~b}$ was the closest to the ideal dimension. Furthermore, the study also found that an imbalanced size of sprue and runner will produce unstable molten metal flow, which resulted in interference of static pressure, velocity magnitude, turbulent viscosity, wall and shear stress. Such criteria will result in rough surface finish and inherent accuracy of the end product where these have been presented in the results obtained from Concept $3 \mathrm{c}$ which was designed with the sprue and riser located on top of the connector of the hand wheel. For future development, it is suggested that the hand wheel should be designed according to the real dimension so that the results can be more accurate. The material should also be changed to stainless steel in order to improve corrosion and rust resistance. Last but not least, it is also recommended to use a metal spray on the rapid prototyping hand wheel pattern in order to increase the quality of the surface finish of the pattern and also the casting product.

\section{ACKNOWLEDGEMENTS}

The authors are grateful to all those who have assisted directly or indirectly to complete this project at the Universiti Teknikal Malaysia Melaka.

\section{REFERENCES}

[1] Jain P, Kuthe A. Feasibility study of manufacturing using rapid prototyping: FDM approach. Procedia Engineering. 2013;63:4-11.

[2] Baligidad SM, Krishnamurthy N, Narendra N, Srinivasan A. Sand Casting: Conventional And Rapid Prototyping Manufacturing Approaches. International Journal of Research in Engineering and Technology. 2014;3.

[3] Iqbal M, Patel S, Vidyarthee G. Simulation of casting and its validation by experiments. International Journal of Engineering Sciences \& Research Technology. 2014;3:555-65.

[4] Roni Sahroni T, Mohd Shahir K, Amran M, Ali M, Effendi M. Design and optimization of runner and gating systems for permanent mould casting. 2014.

[5] Khirsariya N, Kagathra M, Mandaliya P. Reduction of shrinkage defect in valve body casting using simulation software. International Journal of Engineering Sciences \& Research Technology. 2014:1-14.

[6] Chaudhari S, Thakkar H. Review on Analysis of Foundry Defects for Quality Improvement of Sand Casting. International Journal of Engineering Research and Applications. 2014;4:615-8. 
[7] Zhang Y, Bernard A. Grouping parts for multiple parts production in Additive Manufacturing. Procedia CIRP. 2014;17:308-13.

[8] Kakde NU, Tumane AS. Development of customized innovative product using fused deposition modeling technique of rapid prototyping and investment casting. National Conference on Innovative Paradigms in Engineering and Technology, NY2012. p. 27-30.

[9] Achillas C, Aidonis D, Iakovou E, Thymianidis M, Tzetzis D. A methodological framework for the inclusion of modern additive manufacturing into the production portfolio of a focused factory. Journal of Manufacturing Systems. 2015;37:32839.

[10] Jijotiya D, Verma PL. A survey of performance based advanced rapid prototyping techniques. Sch J Eng Tech. 2013;1:4-12. 